\title{
Migration of a tumor thrombus promptly detected by transesophageal echocardiography during radical nephrectomy concomitant with inferior vena cava thrombectomy: a case report
}

\author{
Kyungmi Kim", Jun-Young Park', Jihion Yu', Jin Young Chon², Sukyung Chung ${ }^{2}$, Jai-Hyun Hwang ${ }^{1}$, \\ Young-Kug Kim ${ }^{1}$ \\ ${ }^{1}$ Department of Anesthesiology and Pain Medicine, Asan Medical Center, University of Ulsan College of Medicine, Seoul, ${ }^{2}$ Department \\ of Anesthesiology and Pain Medicine, Yeouido St. Mary's Hospital, College of Medicine, The Catholic University of Korea, Seoul, Korea
}

Received September 3, 2019

Revised November 11, 2019

Accepted November 12, 2019

\section{Corresponding author}

Jun-Young Park

Department of Anesthesiology and Pain Medicine, Asan Medical Center, University of Ulsan College of Medicine, 88, Olympic-ro 43-gil, Songpa-gu, Seoul 05505, Korea

Tel: +82-2-3010-1415

Fax: +82-2-3010-6790

E-mail: parkjy@amc.seoul.kr

ORCID:

http://orcid.org/0000-0003-4476-4945

\begin{abstract}
A 60-year-old man with a $12 \mathrm{~cm}$ mass involving the right kidney and a renal vein tumor thrombus extending to the intrahepatic inferior vena cava (IVC), was scheduled for a radical nephrectomy concomitant with an IVC thrombectomy. During the operation, through intraoperative transesophageal echocardiography (TEE) monitoring, a migrating tumor thrombus was promptly detected. After the operation, a filling defect in the posterior basal segmental or subsegmental pulmonary arteries of the lower lobe of the right lung was observed on chest computed tomography. Intraoperative TEE provides additional information to help guide the surgical intervention and medical treatment.
\end{abstract}

Keywords: Venous thrombosis; Pulmonary embolism; Carcinoma; Renal cell; Echocardiography; Transesophageal

\section{INTRODUCTION}

Renal cell carcinoma (RCC), the ninth most common malignancy, is associated with a propensity for vascular invasion, with up to $10 \%$ of patients having an associated venous tumor thrombus involving the renal vein or the inferior vena cava (IVC) and approximately $1 \%$ having a tumor thrombus that extends into the right atrium [1-3]. Early diagnosis and surgical treatment are essential for managing RCC, which has the highest mortality rate among urological cancers.

Mortality rates after radical nephrectomy, in patients with concomitant IVC thrombectomy, range from $5 \%$ to $12.5 \%$ for a higher-level thrombus, depending on patient comorbidities and tumor characteristics [4]. Even when the location of a tumor thrombus has been determined by preoperative evaluations, small or large ruptures and migration of the tumor thrombus may occur during surgery [5].

Herein, we present a case of the immediate detection of

This is an Open Access article distributed under the terms of the Creative Commons Attribution Non-Commercial License (http://creativecommons.org/licenses/by-nc/4.0) which permits unrestricted noncommercial use, distribution, and reproduction in any medium, provided the original work is properly cited.

Copyright (c) Medical Biological Science and Engineering. 
tumor thrombus migration by intraoperative transesophageal echocardiography (TEE) monitoring during radical nephrectomy with concomitant IVC thrombectomy.

\section{CASE REPORT}

A 60-year-old man was diagnosed with a $12 \mathrm{~cm}$ mass involving the right kidney, by preoperative computed tomography (CT). Renal sinus fat invasion, renal vein invasion, and a renal vein tumor thrombus extending to the intrahepatic inferior vena cava (IVC) were also observed (Fig. 1A and B). The patient was scheduled for radical nephrectomy through a laparotomy and IVC thrombectomy by urological and hepatobiliary surgeons. No evidence of distant metastatic disease was found. His medical history was unremarkable, except for hypertension.

After the routine induction of anesthesia, a continuous TEE was applied to examine the IVC tumor thrombus. The mass appeared homogeneous, with a mobile tailing edge and it occupied the lumen of the intrahepatic IVC (Fig. 2A).
The IVC was not dilated and there was no evidence of flow obstruction. Based on the extent of IVC involvement seen on the TEE, the surgical team chose to perform a full laparotomy with an extended Chevron incision across the midline.

The hepatobiliary surgeons mobilized the liver and dissected the proximal IVC. While isolating and clamping the IVC, transient hypotension was observed (Table 1). When IVC clamping was completed, continuous TEE monitoring revealed that the edge of the tumor thrombus had split away from the main mass and migrated towards the right atrium. The procedure was interrupted and the TEE was examined to search for the thrombus fragment in the right atrium, right ventricle, and pulmonary artery. However, it was not detected. During this time, the patient's heart rate, electrocardiogram, and central venous pressure remained unchanged from baseline values (Table 1). The end-tidal carbon dioxide concentration also remained constant, at $29 \mathrm{mmHg}$. The partial pressure of oxygen and carbon dioxide, according to arterial blood gas analysis, were 260
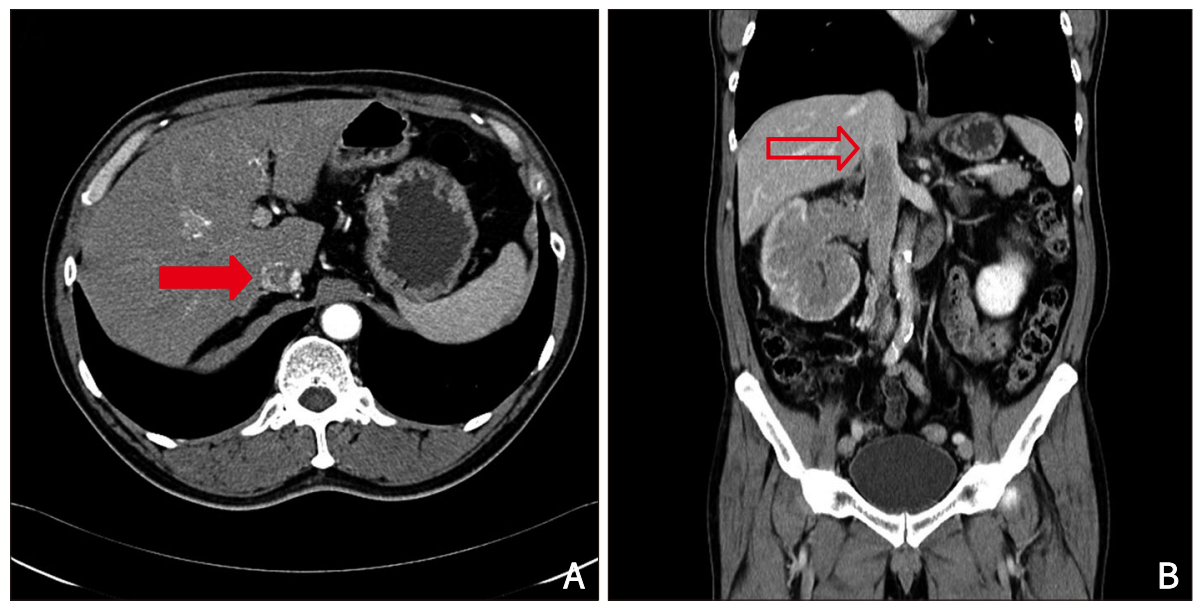

B
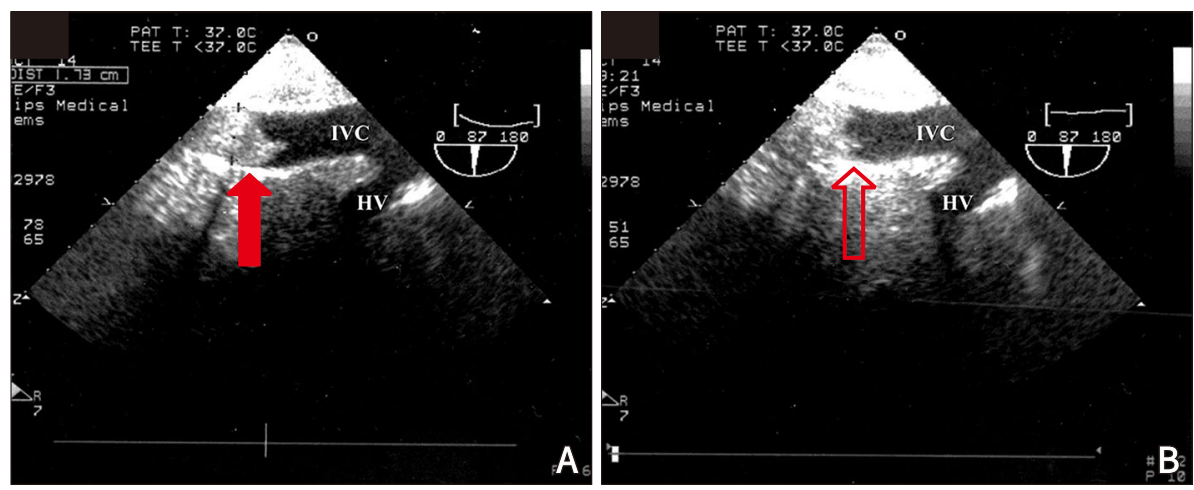

Fig. 1. Preoperative contrast-enhanced abdominal computerized tomography scan shows a mass involving the right kidney, with renal sinus fat and renal vein invasion that extends to the intrahepatic inferior vena cava. (A) Axial view of abdominal computerized tomography. Note that the tumor thrombus entirely filled the intrahepatic inferior vena cava (filled arrow). (B) Coronal view of abdominal computerized tomography. The tumor thrombus invaded the intrahepatic inferior vena cava (blank arrow).
Fig. 2. (A) The transgastric inferior vena cava long axis view at 87 degrees shows the inferior vena cava tumor thrombus. The tumor thrombus has a mobile tailing edge and occupies the lumen of the intrahepatic inferior vena cava (filled arrow). (B) After clamping, the thrombus in the inferior vena cava had irregular margins and an immobile tail (blank arrow), as seen on the transgastric inferior vena cava long axis view at 87 degrees. IVC, inferior vena cava; HV, hepatic vein 
Table 1. Variables monitored intraoperatively

\begin{tabular}{|c|c|c|c|}
\hline Variables & Baseline & $\begin{array}{l}\text { Vena cava } \\
\text { clamp }\end{array}$ & $\begin{array}{l}\text { Thrombus } \\
\text { migration }\end{array}$ \\
\hline $\begin{array}{l}\text { Systolic arterial blood pressure } \\
(\mathrm{mmHg})\end{array}$ & 105 & 75 & 110 \\
\hline $\begin{array}{l}\text { Diastolic arterial blood pressure } \\
(\mathrm{mmHg})\end{array}$ & 60 & 40 & 60 \\
\hline $\begin{array}{l}\text { Mean arterial blood pressure } \\
(\mathrm{mmHg})\end{array}$ & 75 & 52 & 77 \\
\hline Central venous pressure $(\mathrm{mmHg})$ & 4 & 5 & 10 \\
\hline Heart rate (beats/min) & 95 & 105 & 95 \\
\hline Cardiac index $\left(\mathrm{L} / \mathrm{min} / \mathrm{m}^{2}\right)$ & 3.1 & 3.3 & 3.9 \\
\hline Stroke volume index $\left(\mathrm{mL} / \mathrm{m}^{2}\right)$ & 31 & 35 & 40 \\
\hline Stroke volume variation (\%) & 11 & 6 & 5 \\
\hline $\begin{array}{l}\text { Systemic vascular resistance } \\
\left(\text { dynes } / \text { second } / \mathrm{cm}^{-5}\right)\end{array}$ & 1,116 & 965 & 944 \\
\hline Body temperature $\left({ }^{\circ} \mathrm{C}\right)$ & 35 & 36.4 & 35.5 \\
\hline $\mathrm{ETCO}_{2}(\mathrm{mmHg})$ & 28 & 29 & 29 \\
\hline
\end{tabular}

$\mathrm{mmHg}$ and $39 \mathrm{mmHg}$, respectively, immediately after this episode. However, we could not exclude the possibility of a pulmonary embolism, because the remaining thrombus had irregular margins, without a mobile tail (Fig. 2B). We recommended anticoagulation therapy and performed pulmonary embolic CT. No significant hemodynamic changes were observed following intravenous administration of 4,000 units of heparin. Subsequently, the surgeons resumed the procedure. The right kidney and the IVC tumor were extracted under continuous real-time TEE monitoring. The IVC clamp was released after TEE confirmed the absence of any residual tumor in the IVC. The procedure was completed without further complications and the patient was transferred to the intensive care unit for postoperative management.

The postoperative pulmonary embolic CT revealed a filling defect in the posterior basal segmental or subsegmental pulmonary arteries of the lower lobe of the right lung (Fig. 3). This was correlated with a pulmonary thromboembolism; therefore, the patient was placed on anticoagulation therapy. The remainder of his in-hospital stay was uneventful and he was discharged 10 days later.

\section{DISCUSSION}

RCC can typically invade the vascular system and form a tumor thrombus [6]. Tumor embolization is a fatal complication, with an overall incidence of $1.5 \%$ and a $3.5 \%$ in-

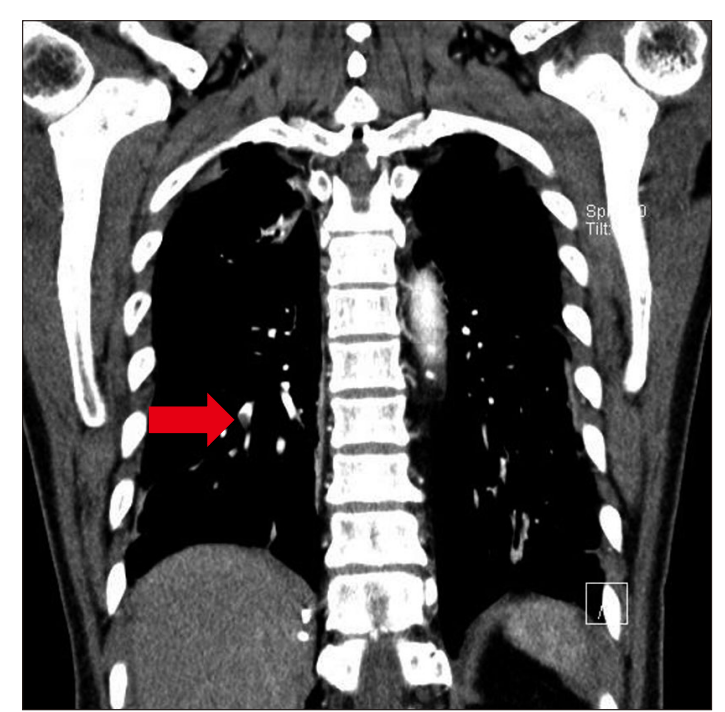

Fig. 3. Postoperative pulmonary embolic computed tomography shows a filling defect (arrow) in the posterior basal segmental or subsegmental pulmonary arteries of the lower lobe of the right lung.

cidence in cases of RCC with a thrombus invading the IVC [7]. A tumor thrombus found in the renal vein extending $<2 \mathrm{~cm}$ within the IVC is staged as level I, according to the classification system described by Neves and Zincke [8]; an intrahepatic thrombus is staged as level II; an intrahepatic IVC thrombus below the diaphragm is staged as level III; and an IVC tumor thrombus extending above the diaphragm is staged as level IV. For IVC tumor thrombus levels I to IV, adverse event rates have been noted as $18 \%, 20 \%$, $26 \%$, and $47 \%$, respectively [9]. Thus, the prompt diagnosis and removal of tumor thrombi are crucial for the survival of patients undergoing radical nephrectomy and tumor thrombectomy.

TEE monitoring during the surgical management of an RCC invading the IVC facilitates successful embolectomy and subsequently, aids the perioperative management of persistent right ventricular dysfunction [10]. While the initial intraoperative uses of TEE were limited to the detection of ischemic wall motion abnormalities and intracardiac air during cardiac surgery, recently, its role has extended to assessing systolic and diastolic functions of the left ventricle, right ventricular function, and left ventricular outflow tract obstruction with systolic anterior motion of the mitral valve after cardiac procedures [11]. Moreover, according to Memtsoudis and colleagues, TEE may provide additional diagnostic information for patients with intraoperative cardiac arrest and may directly guide specific and potentially 
life-saving therapy [12]. TEE has been successfully used for the primary suspected diagnosis of an underlying pathological process in 19 patients, including nine with thromboembolic events, six with acute myocardial ischemia, two with hypovolemia, and two with pericardial tamponade [12]. The continued use of TEE monitoring during the intraoperative period has changed the role of the anesthesiologist from that of a service provider to an integral part of the decision-making process in the operating room [13]. Therefore, TEE has a significant impact on surgical decision-making and treatment [14].

Intraoperative pulmonary emboli in patients with an RCC invading the IVC and forming a thrombus are rare (1.49\%), but are associated with high a rate of morbidity and mortality (75\%) [7]. In this case, continuous intraoperative TEE monitoring promptly identified the migration of the tumor thrombus just after IVC clamping. Although surgeons were unable to diagnose the pulmonary thromboembolism with TEE while the tumor thrombus was migrating, TEE helped to guide the surgical intervention and medical treatment during radical nephrectomy concomitant with IVC thrombectomy. For these reasons, TEE monitoring should be used during IVC tumor resection. To support this, recent guidelines state that TEE is indicated in procedures where a sudden deterioration of cardiac function may occur [15]. According to the practice guidelines for perioperative TEE in adult patients without contraindications, it may be used when the nature of the planned non-cardiac surgery or the patient's known or suspected cardiovascular pathology may result in severe hemodynamic, pulmonary, or neurologic compromise [15]. Therefore, intraoperative TEE can be performed routinely during the resection of an RCC invading the IVC.

In conclusion, we promptly detected the migration of a tumor thrombus by TEE during radical nephrectomy with IVC thrombectomy. Intraoperative TEE monitoring provides good information on the early diagnosis and treatment of a thromboembolism. Thus, TEE is an essential monitoring tool during surgical resection of an RCC invading the IVC.

\section{CONFLICT OF INTEREST}

No potential conflict of interest relevant to this article was reported.

\section{REFERENCES}

1. Boorjian SA, Sengupta S, Blute ML. Renal cell carcinoma: vena caval involvement. BJU Int 2007;99:1239-44.

2. Gupta K, Miller JD, Li JZ, Russell MW, Charbonneau C. Epidemiologic and socioeconomic burden of metastatic renal cell carcinoma (mRCC): a literature review. Cancer Treat Rev 2008;34:193-205.

3. Jonasch E, Gao J, Rathmell WK. Renal cell carcinoma. BMJ 2014;349:g4797.

4. Parra J, Drouin SJ, Hupertan V, Comperat E, Bitker MO, Rouprêt M. Oncological outcomes in patients undergoing radical nephrectomy and vena cava thrombectomy for renal cell carcinoma with venous extension: a single-centre experience. Eur J Surg Oncol 2011;37:422-8.

5. Chen H, Ng V, Kane CJ, Russell IA. The role of transesophageal echocardiography in rapid diagnosis and treatment of migratory tumor embolus. Anesth Analg 2004;99:357-9.

6. Wotkowicz C, Wszolek MF, Libertino JA. Resection of renal tumors invading the vena cava. Urol Clin North Am 2008; 35:657-71.

7. Shuch B, Larochelle JC, Onyia T, Vallera C, Margulis D, Pantuck AJ, et al. Intraoperative thrombus embolization during nephrectomy and tumor thrombectomy: critical analysis of the University of California-Los Angeles experience. J Urol 2009;181:492-8; discussion 498-9.

8. Neves RJ, Zincke H. Surgical treatment of renal cancer with vena cava extension. Br J Urol 1987;59:390-5.

9. Lawindy SM, Kurian T, Kim T, Mangar D, Armstrong PA, Alsina $\mathrm{AE}$, et al. Important surgical considerations in the management of renal cell carcinoma (RCC) with inferior vena cava (IVC) tumour thrombus. BJU Int 2012;110:926-39.

10. Larney V, Charles R, Brown AS, Leonard IE. Value of transoesophageal echocardiography for diagnosis of intraoperative tumour embolization. Anaesth Intensive Care 2006;34:797-800.

11. Akiyama K, Arisawa S, Ide M, Iwaya M, Naito Y. Intraoperative cardiac assessment with transesophageal echocardiography for decision-making in cardiac anesthesia. Gen Thorac Cardiovasc Surg 2013;61:320-9.

12. Memtsoudis SG, Rosenberger P, Loffler M, Eltzschig HK, Mizuguchi A, Shernan SK, et al. The usefulness of transesophageal echocardiography during intraoperative cardiac arrest in noncardiac surgery. Anesth Analg 2006;102:1653-7.

13. Bergman R, Mahmood F. Anesthesiologists and transesophageal echocardiography: echocardiographers or echocardiologists? J Cardiothorac Vasc Anesth 2013;27:627.

14. Montealegre-Gallegos M, Mahmood F. Intraoperative transesophageal echocardiography: monere to decidere. J Cardiothorac Vasc Anesth 2014;28:1700-1. 
15. American Society of Anesthesiologists and Society of Cardiovascular Anesthesiologists Task Force on Transesophageal Echocardiography. Practice guidelines for perioperative transesophageal echocardiography. An updated report by the American Society of Anesthesiologists and the Society of Cardiovascular Anesthesiologists Task Force on Transesophageal Echocardiography. Anesthesiology 2010;112:1084-96. 